\title{
The efficacy of treating patients with non-metastatic gastric linitis plastica using surgery with chemotherapy and/or radiotherapy
}

\author{
Xueru Song ${ }^{1}$, Yan Shi ${ }^{2}$, Tao Shi ${ }^{1}$, Baorui Liu ${ }^{1}$, Jia Wei $^{1}$, Jiping Wang ${ }^{3}$ \\ ${ }^{1}$ The Comprehensive Cancer Centre of Nanjing Drum Tower Hospital, The Affiliated Hospital of Nanjing University Medical School, Nanjing, \\ China; ${ }^{2}$ Department of Oncology, Ruijin Hospital, School of Medicine, Shanghai Jiao Tong University, Shanghai, China; ${ }^{3}$ Division of Surgical \\ Oncology, Department of Surgery, Brigham and Women's Hospital, Harvard Medical School, Boston, MA, USA \\ Contributions: (I) Conception and design: X Song, J Wei, J Wang; (II) Administrative support: J Wei, J Wang; (III) Provision of study materials: J Wei, \\ J Wang; (IV) Collection and assembly of data: X Song, Y Shi, T Shi; (V) Data analysis and interpretation: X Song, J Wei, Y Shi, T Shi, B Liu; (VI) \\ Manuscript writing: All authors; (VII) Final approval of manuscript: All authors. \\ Correspondence to: Jiping Wang, PhD, MD. Division of Surgical Oncology, Department of Surgery, Brigham and Women's Hospital, Harvard \\ Medical School, 75 Francis Street, Boston, MA, USA. Email: jwang39@bwh.harvard.edu; Jia Wei, PhD, MD. The Comprehensive Cancer \\ Centre of Nanjing Drum Tower Hospital, The Affiliated Hospital of Nanjing University Medical School, 321 Zhongshan Road, Nanjing, China. \\ Email: weijia01627@hotmail.com.
}

Background: To explore the efficacy of treatment strategies for non-metastatic gastric linitis plastica (GLP). Methods: Patients with non-metastatic GLP from 2004 to 2014 were identified from the National Cancer Database (NCDB). We compared overall survival (OS) of those patients who received different treatments, including surgery alone, a combination of surgery with chemotherapy and/or radiotherapy $(S+C / R)$, chemotherapy and/or radiotherapy (C/R), and no treatment.

Results: The cohort included 474 patients with non-metastatic GLP. Overall, the median survival was significantly different among four groups (13.90 months in $\mathrm{S}+\mathrm{C} / \mathrm{R}, 8.38$ months in surgery alone, 8.94 months in $\mathrm{C} / \mathrm{R}$ and 2.50 months in no treatment). Then, we compared the efficacy of surgery alone and surgery with postoperative chemotherapy and/or radiotherapy $(\mathrm{S}+$ post $\mathrm{C} / \mathrm{R})$. When the tumor size was greater than $8 \mathrm{~cm}$ in stage III patients, $\mathrm{S}+$ post $\mathrm{C} / \mathrm{R}$ was associated with a better survival benefit than surgery alone. $\mathrm{S}+$ post $\mathrm{C} / \mathrm{R}$ also conferred an obvious survival advantage compared to surgery alone for R0 patients with positive lymph nodes and patients with positive margins.

Conclusions: Surgery plays the fundamental role in improving the OS of patients with non-metastatic GLP. $S+$ post $\mathrm{C} / \mathrm{R}$ would benefit patients in stage III with large-sized tumors $(>8 \mathrm{~cm})$, patients with negative margins and positive lymph nodes, and/or patients with positive margins.

Keywords: Gastric cancer; linitis plastica; surgery; survival

Submitted Mar 24, 2020. Accepted for publication Aug 17, 2020.

doi: $10.21037 / \mathrm{atm}-20-2785 \mathrm{~b}$

View this article at: http://dx.doi.org/10.21037/atm-20-2785b

\section{Introduction}

Gastric linitis plastica (GLP) is a type of diffuse gastric carcinoma characterized by a macroscopically segmental or diffuse thickened gastric wall and scattered infiltration of tumor cells under microscopy $(1,2)$. Since Dr. William Brinton defined linitis plastica in 1859 (3), the definition of GLP has changed several times and remains controversial (2). As a result, the incidence of GLP remains inaccurate. GLP is a relatively rare type of gastric cancer. However, an increasing incidence of GLP in the USA and China has been reported recently (4). Compared with other types of gastric cancer, GLP has unique clinical and 
pathological characteristics. It was found that in GLP, up to $90 \%$ of cancer-associated fibroblasts interacted with poorly differentiated cells, poorly cohesive cells, and/or signet ring cells in a complex model, eventually leading to diffusely fibromatous submucosal and muscular layers (2). The unique biological behavior of GLP results in it being more aggressive and having higher risks of perineural invasion, nodal metastasis, peritoneal dissemination, and direct invasion into surrounding organs (5-7). In addition, lack of mucosal alteration and unclear margins result in delayed diagnosis, leading to patients having less chance to receive curative surgery.

Current guidelines for the treatment of gastric cancer are based mainly on American Joint Committee on Cancer (AJCC) staging rather than gastric cancer typing. So the treatment strategies for GLP are referred to the National Comprehensive Cancer Network (NCCN) guidelines for gastric cancer. However, due to GLP's unique biological behavior and dismal prognosis, exploring optimal treatment strategies has been an active and controversial field (7-14). Some researchers have found that GLP is a non-surgical entity $(7,9,12)$. Pedrazzani et al. studied 92 GLP patients who underwent surgical exploration. Only $27.5 \%$ patients received R0 resection. The overall median survival was 5.7 months, although for R0 resection patients the median survival reached 15.8 months (9). On the other hand, optimistic researchers have reported that surgery is the only hope to achieve the best survival benefit $(8,11,13)$. Schauer et al. reported the surgical experience in 120 GLP patients, of which $30.8 \%$ received $\mathrm{R} 0$ resection. The overall median survival was 8 months whereas those who achieved $\mathrm{R} 0$ resection experienced 17 months median survival (8). A recent study demonstrated a multimodal strategy involving both surgery and adjuvant chemotherapy provides the best oncologic outcomes (10). The controversy surrounding treatment strategies may be attributed to the ambiguous definition of GLP, relatively small sample size, and lack of discussion on the different stages of GLP in these studies. Therefore, it is necessary to identify the optimal therapy for GLP with different characteristics to achieve the best therapeutic effect while avoiding excessive medical treatment.

For these reasons, our study explored the efficacy of several strategies including surgery alone, chemotherapy and/or radiotherapy, and the combination of surgery and chemotherapy/radiotherapy, for patients with nonmetastatic GLP in the National Cancer Database (NCDB). Moreover, we compared the therapeutic efficacy of surgery alone and surgery with postoperative chemotherapy and/ or radiotherapy, according to the following four variables independently: cancer stage, tumor size, resection margins and regional lymph nodes. We present the following article in accordance with the STROBE reporting checklist (available at http://dx.doi.org/10.21037/atm-20-2785b).

\section{Methods}

\section{Data source and study subjects}

The National Cancer Database (NCDB), which collects information on almost $70 \%$ of all newly diagnosed invasive cancer cases in the United States, is one of the largest cancer outcome databases in the world $(15,16)$. For this study, GLP participant user file from 2004 to 2014 was identified using the $3 r d$ International Classification of Diseases for Oncology (ICD-O-3) codes. We restaged the TNM classification of the patients according to the American Foint Committee on Cancer Staging Manual (AFCC), 8th Edition from 2017 (17). In this article, pathologic staging was mainly used, which was supplemented by clinical staging when pathological information was unavailable. $\mathrm{N}$ stage was divided according to the number of regional lymph node metastases provided by the database. T stage was transformed according to the tumor extension criteria described in different editions of AJCC, including T2b(6th) to T3(8th), T3(6th) to $\mathrm{T} 4 \mathrm{a}(8 \mathrm{th}), \mathrm{T} 4$ (6th) to $\mathrm{T} 4 \mathrm{~b}(8 \mathrm{th})$. The study was conducted in accordance with the Declaration of Helsinki (as revised in 2013).

\section{Statistical analysis}

Demographic variables were compared using $\chi^{2}$ test and Fisher's exact test for categorical variables, and ANOVA test for continuous variables. The main outcome assessed in this study was overall survival (OS), which was evaluated using Kaplan-Meier survival curves and log-rank tests. Univariate and multivariate Cox regression models were performed to quantify the relationship between patient characteristics and OS. Univariate variables were selected for multivariate analysis when the $\mathrm{P}$ value was less than 0.05 . The forest plot was performed to compare the efficacy of surgery with postoperative chemotherapy/radiotherapy versus surgery alone among different non-metastasis GLP subgroups. A $\mathrm{P}$ value $<0.05$ was considered as a statistically significant difference. All analyses were performed using R 3.5.1 (http://www.R-project.org/). 


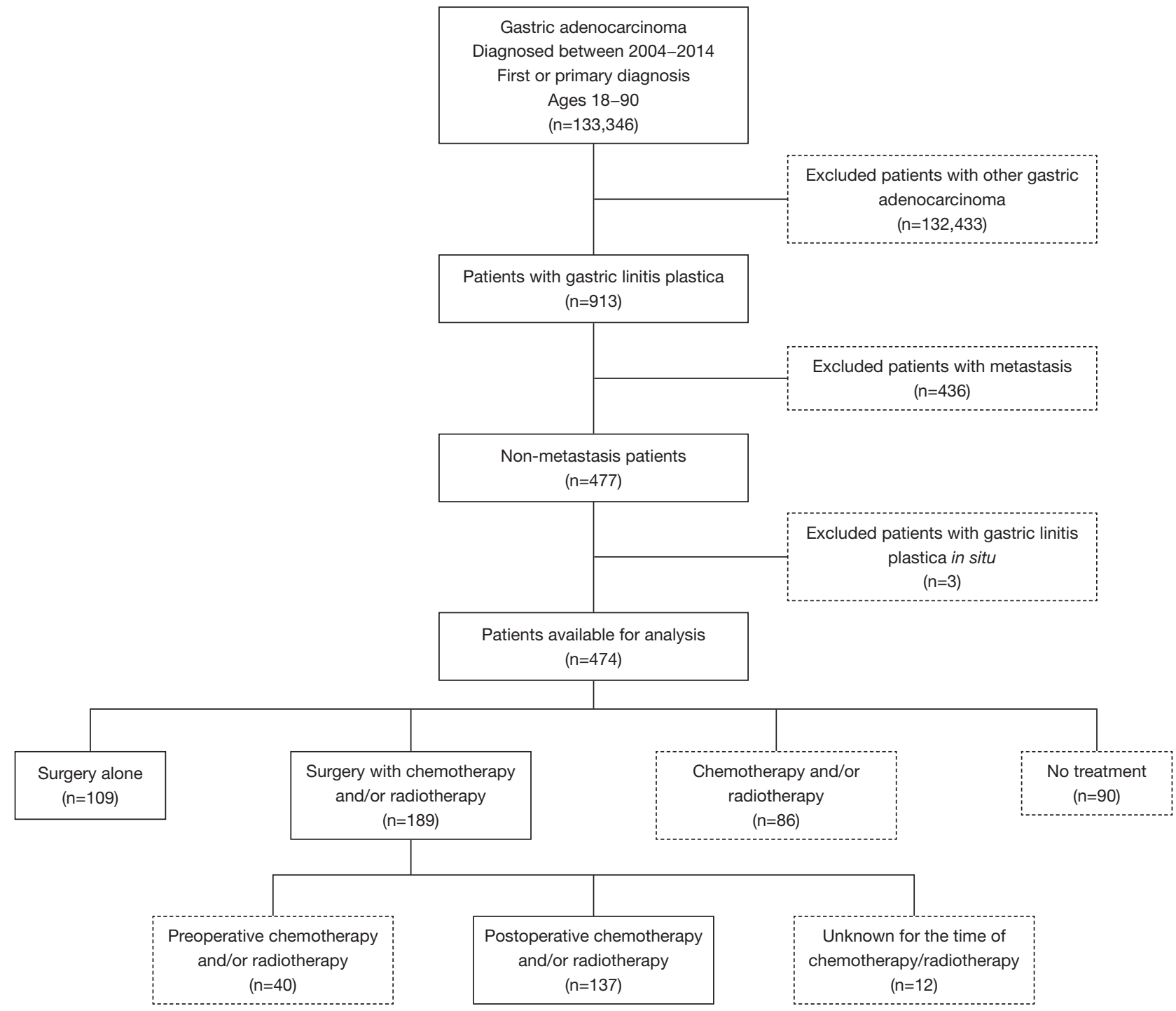

Figure 1 Selection criteria for patient data extracted from the National Cancer Database (NCDB).

\section{Results}

\section{Patients characteristics}

In total, there were 913 patients diagnosed with GLP from 2004 to 2014 in the NCDB database. Patients with GLP in situ $(\mathrm{n}=3)$ or metastasis $(\mathrm{n}=436)$ were excluded from this study. The final cohort included only 474 patients with nonmetastatic GLP. Among them, 109 patients were treated with surgery alone, 189 patients received the combination of surgery and chemotherapy and/or radiotherapy $(\mathrm{S}+$ C/R), 86 patients received chemotherapy and/or radiotherapy $(\mathrm{C} / \mathrm{R})$, and 90 patients were not treated with any of the aforementioned methods (Figure 1).
Clinical information for the relative majority of patients who received $\mathrm{C} / \mathrm{R}$ was lacking (tumor size in $58.14 \%$, histological grade in $34.88 \%$ and stage in $61.63 \%$ patients were unknown; positive lymph nodes and resection were not available). The proportion of patients with a large tumor size $(>8 \mathrm{~cm})$ was similar between patients who received surgery alone and $\mathrm{S}+\mathrm{C} / \mathrm{R}(57.80 \%$ vs. $53.44 \%$, $\mathrm{P}<0.001)$. In addition, the proportion of different stages was similar between patients who received surgery alone and $\mathrm{S}+$ C/R (stage I, $6.42 \%$ vs. $4.76 \%$; stage II, $22.02 \%$ vs. $18.52 \%$; stage III, $62.39 \%$ vs. $69.84 \%$; $\mathrm{P}<0.001)$. The proportion of different resection margins was also similar between patients who received surgery alone and $S+C / R$ [negative 
margins (R0), $40.37 \%$ vs. $56.08 \%$; positive margins (R+), $56.88 \%$ vs. $41.27 \% ; \mathrm{P}=0.03$; Table 1$]$.

\section{Comparison of survival among patients who received different strategies}

Overall, the OS was significantly different among patient groups (median survival: 13.90 months in $\mathrm{S}+\mathrm{C} / \mathrm{R}$, 8.38 months in surgery alone, 8.94 months in $\mathrm{C} / \mathrm{R}$ and 2.50 months in no treatment; 5 -year survival rates: $7.4 \%$ in $\mathrm{S}+\mathrm{C} / \mathrm{R}, 6.4 \%$ in surgery alone, and $0 \%$ in both $\mathrm{C} / \mathrm{R}$ and no treatment, $\mathrm{P}<0.0001$, Figure 2). These results indicated that $\mathrm{S}+\mathrm{C} / \mathrm{R}$ was associated with the best survival outcome in general. Although the median survival between $\mathrm{C} / \mathrm{R}$ and surgery alone were close, only patients who received surgery could have long term survival.

\section{Prognostic factors for non-metastasis GLP patients who received surgery}

Accurate staging is very important for the treatment and prognosis of tumors, which can only be obtained by surgery. Therefore, we performed further analysis on the patients who underwent surgery.

Cox proportional-hazards model analyses were performed to determine the independent prognostic factors that might influence long term survival of non-metastatic GLP patients who received surgery (Table 2). Based on univariate analysis, age more than 65 years (HR 1.66, 95\% CI: $1.30-2.13, \mathrm{P}<0.001$ ), $\mathrm{pN} 1 / 2$ stage (HR 2.32, 95\% CI: $1.61-3.34, \mathrm{P}<0.001), \mathrm{pN} 3$ stage (HR 2.60, 95\% CI: 1.83-3.71, $\mathrm{P}<0.001$ ), stage III (HR 1.95, 95\% CI: 1.44-2.64, $\mathrm{P}<0.001)$ and positive margins $(\mathrm{R}+, \mathrm{HR} 1.99,95 \% \mathrm{CI}$ : $1.55-2.57, \mathrm{P}<0.001)$ were poor prognostic factors. Surgery with postoperative chemotherapy/radiotherapy $(\mathrm{S}+$ post $\mathrm{C} /$ R, HR 0.75 , 95\% CI: $0.58-0.98, \mathrm{P}=0.036$ ) was a protective prognosis factor. Multivariate analysis revealed $\mathrm{S}+$ post $\mathrm{C} /$ $\mathrm{R}$ was an independent prognostic factor (HR 0.61, 95\% CI: $0.45-0.82, \mathrm{P}=0.001)$. Other independent prognosis factors were listed in Table 2.

\section{Subgroup analysis between surgery and surgery with postoperative chemotherapy/radiotherapy}

To avoid the influence of preoperative chemotherapy/ radiotherapy ( $\mathrm{n}=40$, Figure 1 ) in pathological staging, we just estimated the efficacy of $\mathrm{S}+$ post $\mathrm{C} / \mathrm{R}(\mathrm{n}=137$, Figure 1$)$ for non-metastatic GLP patients. In order to analyze the treatment efficacy in patients with different risk factors, patients who underwent surgery alone and $\mathrm{S}+$ post $\mathrm{C} /$ $\mathrm{R}$ were divided into subgroups according to the factors mentioned in Table 2. Cox proportional-hazards model analyses were performed in each subgroup (Figure 3). The results suggested that GLP patients in stage III benefited more from $\mathrm{S}+\mathrm{C} / \mathrm{R}$ compared to surgery alone (HR 0.52, 95\% CI: 0.38-0.72, $\mathrm{P}<0.001$ ), while there was no significant between $\mathrm{S}+$ post $\mathrm{C} / \mathrm{R}$ and surgery alone in stage II patients (HR 1.09, 95\% CI: 0.56-2.13, $\mathrm{P}=0.791$ ). $\mathrm{R}+$ patients yielded an added survival benefit from $\mathrm{S}+$ post $\mathrm{C} / \mathrm{R}$ than surgery alone (HR 0.55, 95\% CI: 0.38-0.79, $\mathrm{P}=0.001$ ), while there was no statistically significant difference between $\mathrm{S}+$ post $\mathrm{C} / \mathrm{R}$ and surgery alone in $\mathrm{R} 0$ patients (HR 0.99, 95\% CI: $0.65-1.50, \mathrm{P}=0.952)$.

\section{Survival benefit of surgery with postoperative chemotherapy/radiotherapy for non-metastatic patients}

Furthermore, we compared the efficacy of S + post C/ $\mathrm{R}$ and surgery alone in different subgroups. In the stage II subgroup, there was no significant difference between patients who received surgery alone and $\mathrm{S}+$ post $\mathrm{C} / \mathrm{R}$ (median survival, 20.2 vs. 16.1 months, $\mathrm{P}=0.79$; Figure S1A). In the stage III group, patients in $\mathrm{S}+$ post $\mathrm{C} / \mathrm{R}$ group had significantly longer survival than those in surgery alone group (median survival, 13.27 vs. $8.18, \mathrm{P}<0.0001$, Figure 4A).

It was reported that the average tumor size of GLP was $8.9 \pm 6.1 \mathrm{~cm}$ (18). Therefore, we assessed whether the tumor size would influence the treatment strategy and prognosis. For stage III patients with a tumor size of $\leq 8 \mathrm{~cm}$, there was no significant difference between surgery alone and $\mathrm{S}+$ post $\mathrm{C} / \mathrm{R}$ (median survival, 13.3 vs. 16.9 months, $\mathrm{P}=0.18$; Figure $\mathrm{S} 1 \mathrm{~B})$. However, in stage III patients with a tumor size of $>8 \mathrm{~cm}$, the therapeutic benefit of $\mathrm{S}+$ post $\mathrm{C} / \mathrm{R}$ was significant with an improvement in median survival of approximately 6.8 months compared to surgery alone $(\mathrm{P}=0.00042$, Figure $4 B)$.

In addition, there were 298 patients who received surgery in total, with 140 patients (46.98\%) among them having positive margins (Table 1). As expected, median survival correlated significantly with resection margins (R0 17.22 vs. $\mathrm{R}+9.79$ months, $\mathrm{P}<0.0001$, Figure $\mathrm{S} 2 \mathrm{~A})$. In $\mathrm{R} 0$ patients, there was no significant difference between surgery alone group and $\mathrm{S}+$ post $\mathrm{C} / \mathrm{R}$ group (median survival, $15.0 \mathrm{vs}$. 19.0 months, $\mathrm{P}=0.95$; Figure $\mathrm{S} 2 \mathrm{~B}$ ). However, the treatment with $\mathrm{S}+$ post $\mathrm{C} / \mathrm{R}$ was associated with better survival 
Table 1 Clinical characteristics of non-metastatic GLP patients

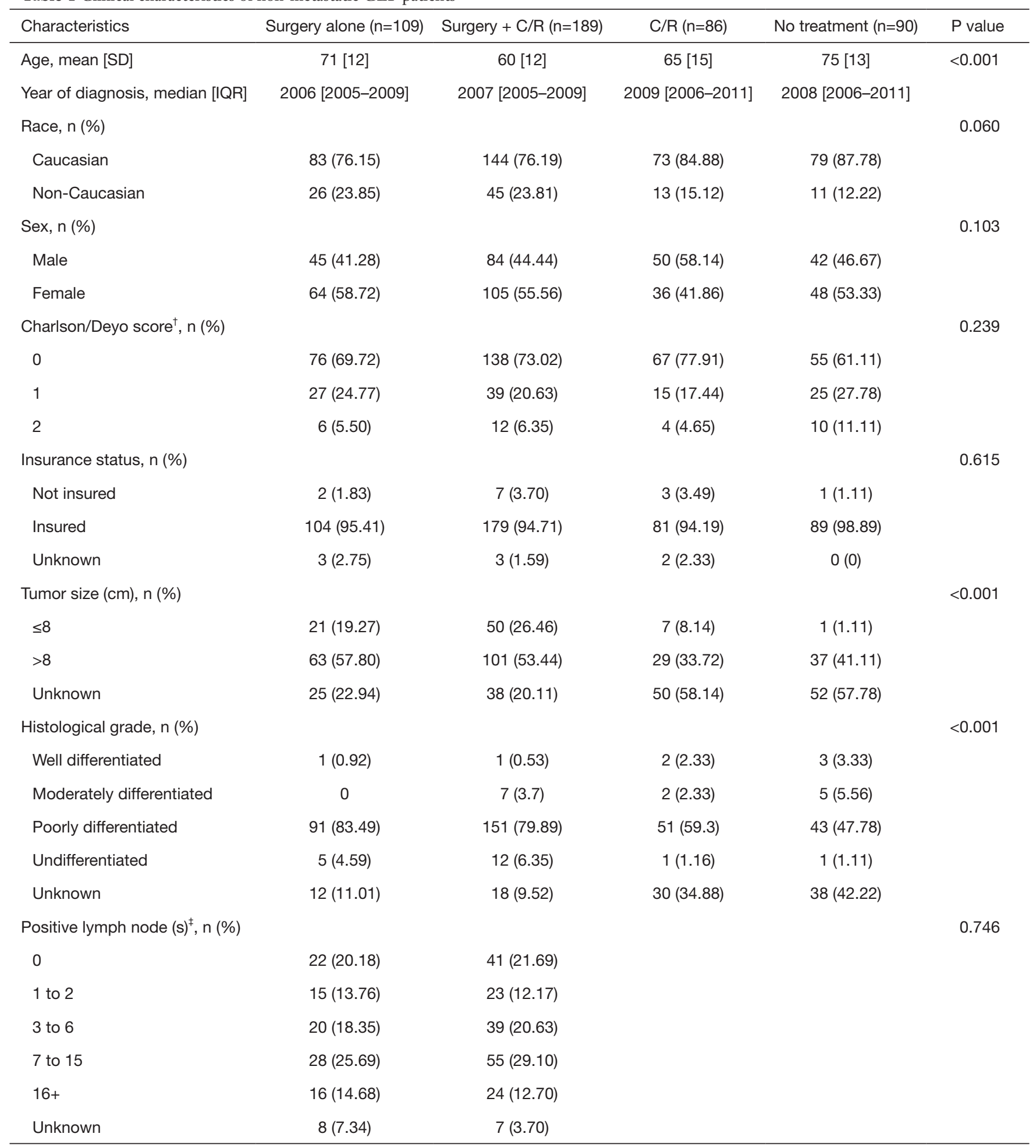

Table 1 (continued) 
Table 1 (continued)

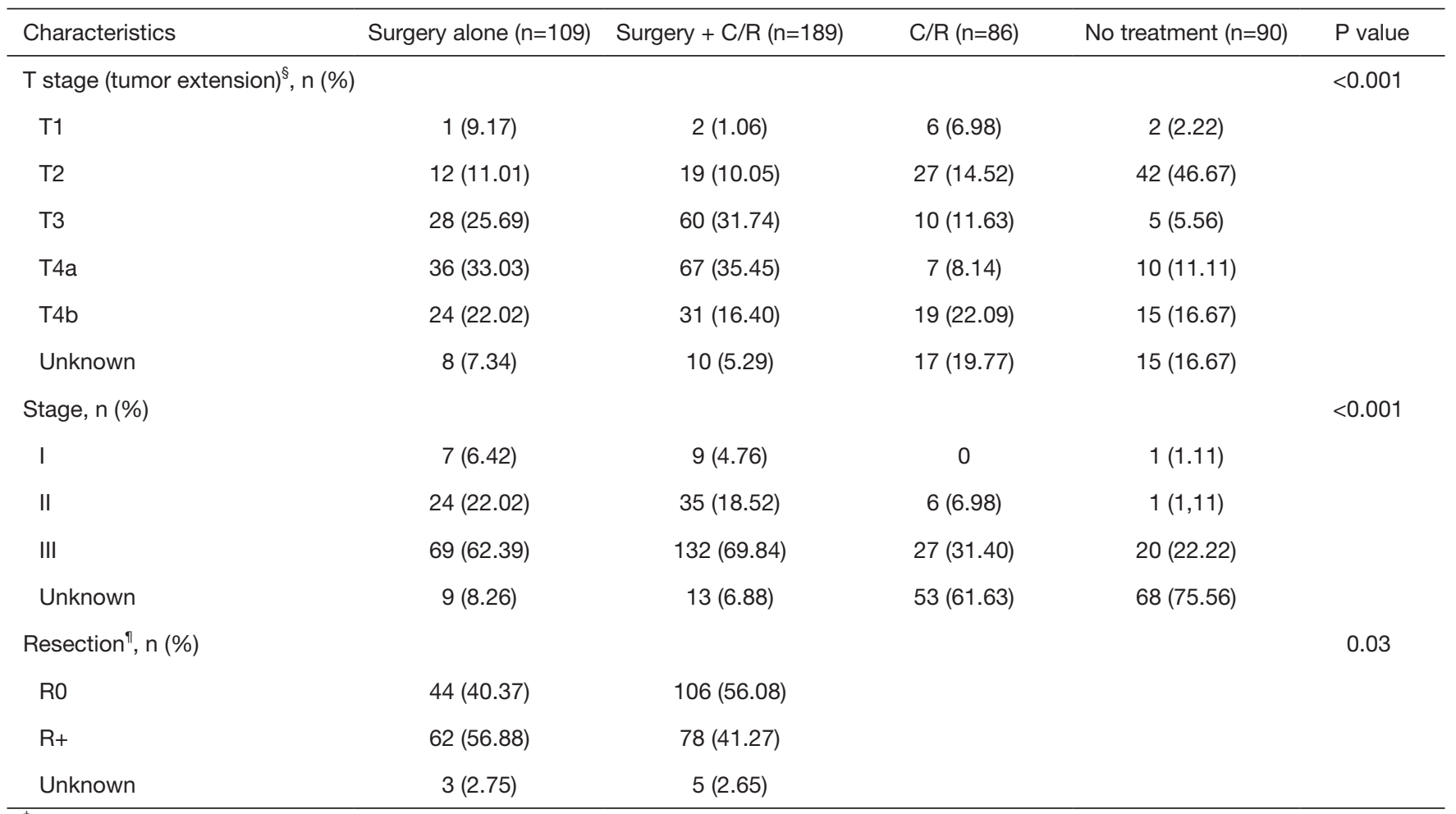

${ }^{\dagger}$, the Charlson/Deyo value is a weighted score derived from the sum of the scores for each of the comorbid conditions listed in the Charlson Comorbidity Score Mapping Table. The data have been truncated to 0, 1, 2 (greater than 1 ); ${ }^{\ddagger}$, the number of positive lymph nodes is based on pathology information only; ", T stage was derived from Collaborative Stage Data Collection System (CS) Extension; ", resection result is based on pathology information only. R0, negative margin; $\mathrm{R}+$, positive margin; $\mathrm{S}+\mathrm{C} / \mathrm{R}$, surgery with chemotherapy or/ and radiation; $\mathrm{C} / \mathrm{R}$, chemotherapy or/and radiation.
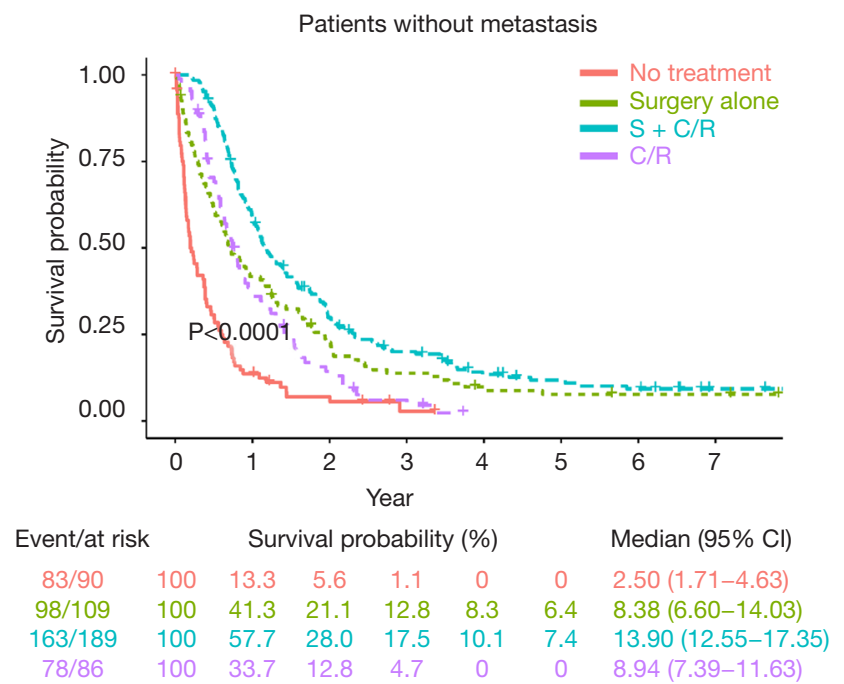

Figure 2 Survival curves of non-metastatic GLP patients according to treatment strategies. S + C/R, surgery with chemotherapy and/ or radiotherapy; $\mathrm{C} / \mathrm{R}$, chemotherapy and/or radiotherapy. than surgery alone in R0 patients with positive lymph nodes (median survival, 16.99 vs. 8.7 months, $\mathrm{P}=0.00078$; Figure $4 C$ ), while there was no significant difference between R0 patients with negative lymph nodes who received surgery alone and $\mathrm{S}+$ post $\mathrm{C} / \mathrm{R}$ (median survival, $57.1 \mathrm{vs}$. 32.2 months, $\mathrm{P}=0.31$; Figure $\mathrm{S} 2 \mathrm{C}$ ). As for $\mathrm{R}+$ patients, the treatment with $\mathrm{S}+$ post $\mathrm{C} / \mathrm{R}$ was associated with better survival than surgery alone (median survival, $11.88 \mathrm{vs}$. 5.67 months, $\mathrm{P}=0.0011$, Figure $4 D$ ). We further explored the efficacy of surgery with postoperative chemotherapy (surgery + chemotherapy) and surgery with postoperative chemoradiotherapy (surgery + chemoradiotherapy). The two strategies showed no significant difference (median survival, 12.9 vs. 10.7 months, $\mathrm{P}=0.99$; Figure $\mathrm{S} 2 \mathrm{D}$ ).

\section{Discussion}

GLP presents an extremely difficult therapeutic challenge due to its unique biological behavior and dismal prognosis. 
Table 2 Cox regression analysis of overall survival of non-metastasis patients receiving surgery ${ }^{\dagger}$

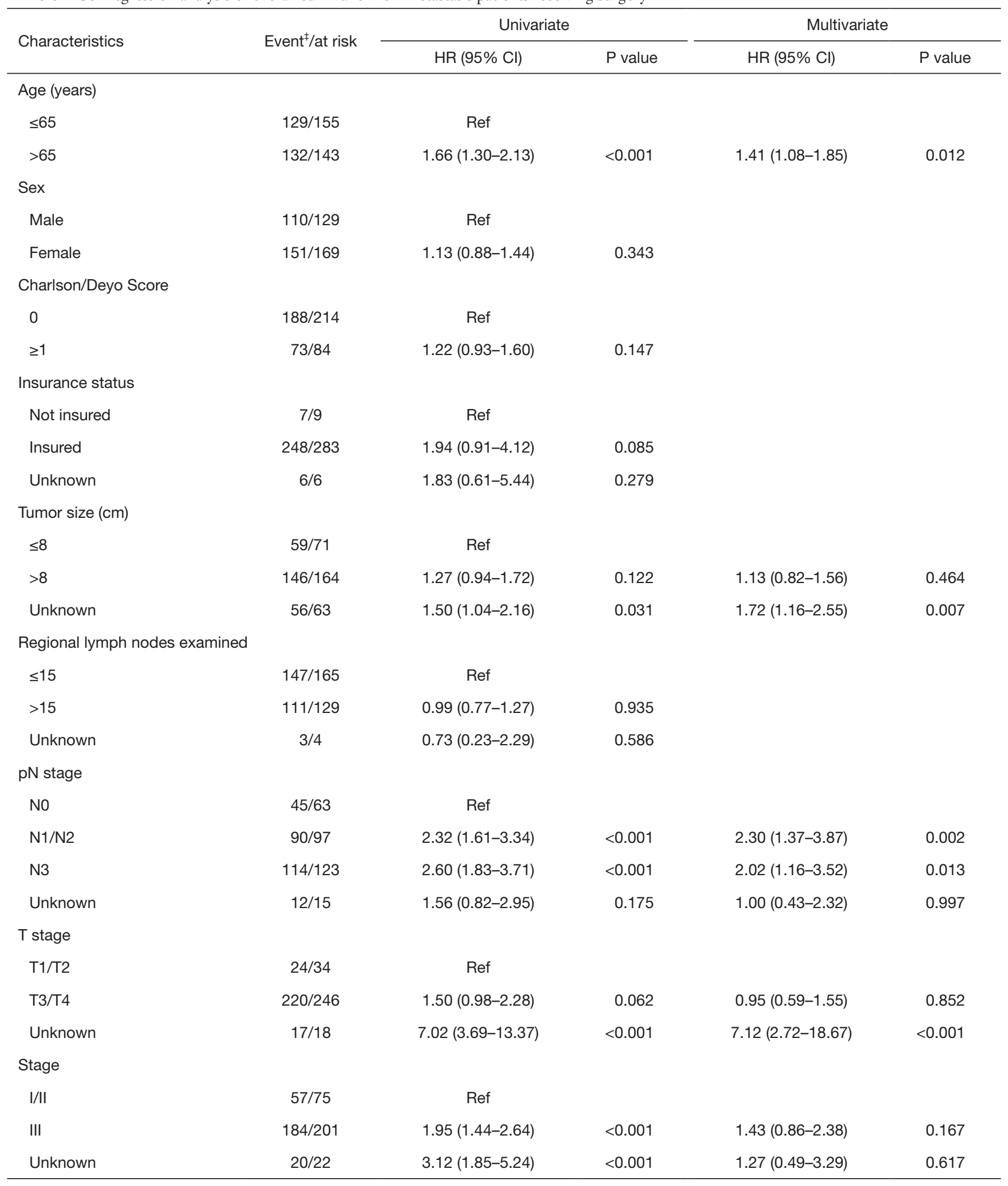

Table 2 (continued) 
Table 2 (continued)

\begin{tabular}{|c|c|c|c|c|c|}
\hline Characteristics & Event ${ }^{\ddagger} /$ at risk & \multicolumn{2}{|c|}{ Univariate } & \multicolumn{2}{|c|}{ Multivariate } \\
\hline \multicolumn{6}{|c|}{ Treatment strategy } \\
\hline Surgery alone & $98 / 109$ & Ref & & & \\
\hline $\mathrm{S}+$ pre $\mathrm{C} / \mathrm{R}$ & $33 / 40$ & $0.69(0.46-1.02)$ & 0.062 & $0.94(0.61-1.45)$ & 0.794 \\
\hline Unknown ${ }^{\S}$ & $9 / 12$ & $0.46(0.23-0.91)$ & 0.025 & $0.42(0.21-0.86)$ & 0.017 \\
\hline \multicolumn{6}{|l|}{ Resection } \\
\hline Ro & $121 / 150$ & Ref & & & \\
\hline $\mathrm{R}+$ & $134 / 140$ & 1.99 (1.55-2.57) & $<0.001$ & $1.65(1.26-2.16)$ & $<0.001$ \\
\hline
\end{tabular}

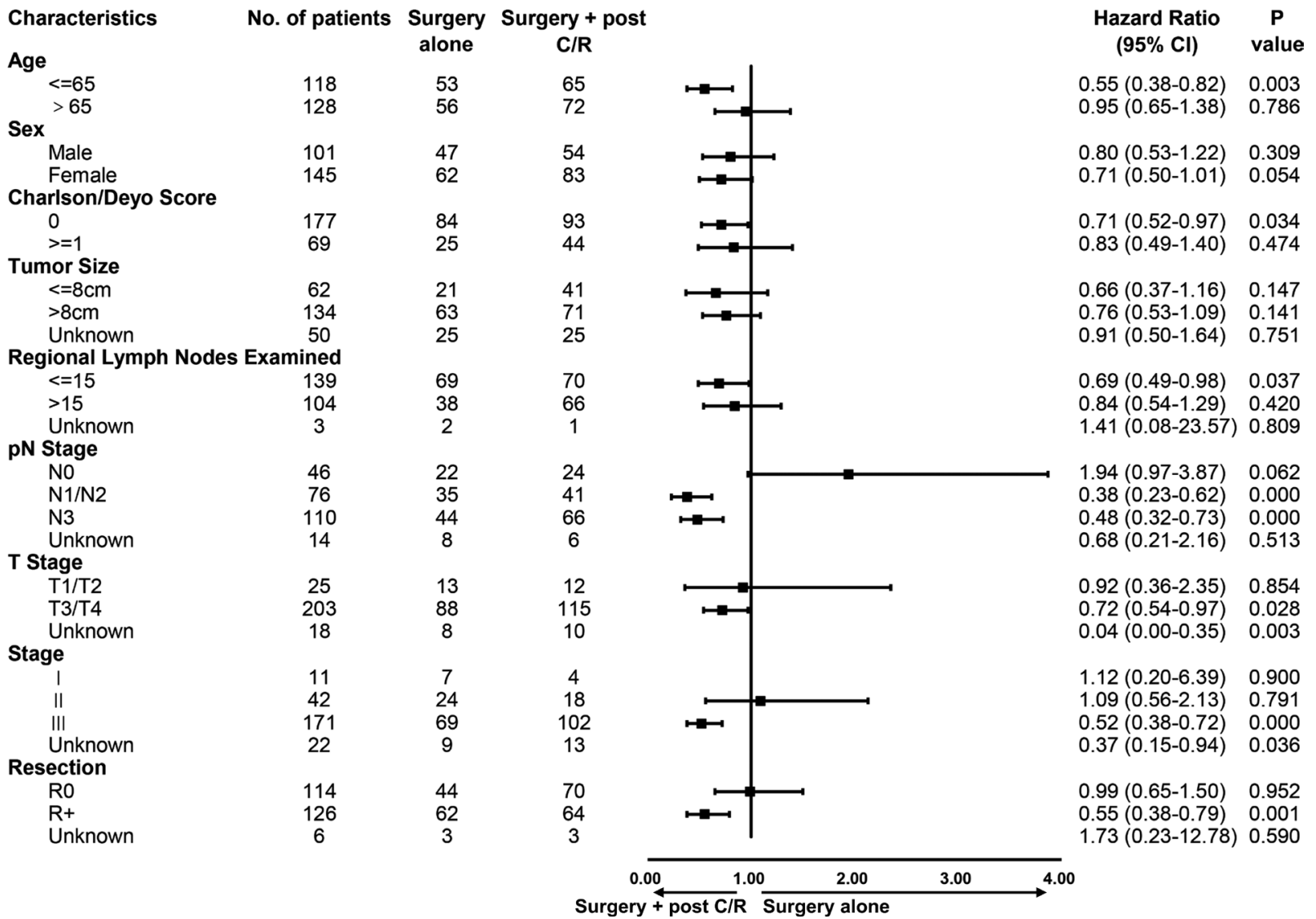

Figure 3 Subgroup analysis of surgery alone and $\mathrm{S}+$ post C/R among non-metastatic GLP patients. S + post C/R, surgery with postoperative chemotherapy and/or radiotherapy. 
A

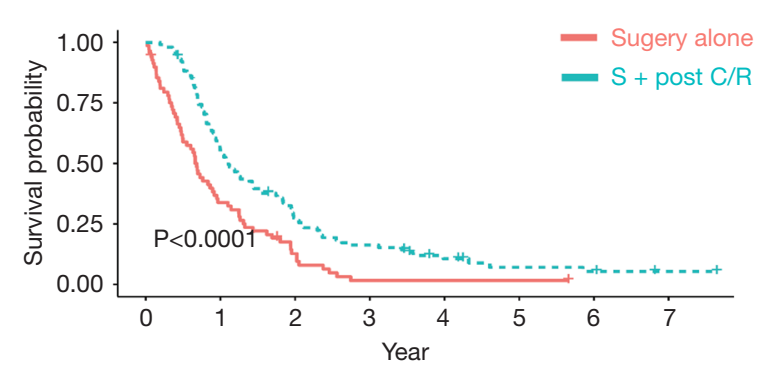

Event/at risk

Survival probability (\%)

Median $(95 \% \mathrm{Cl})$

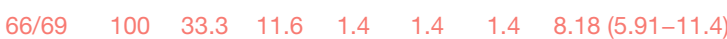

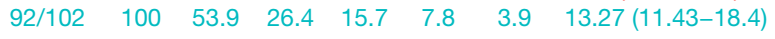

C

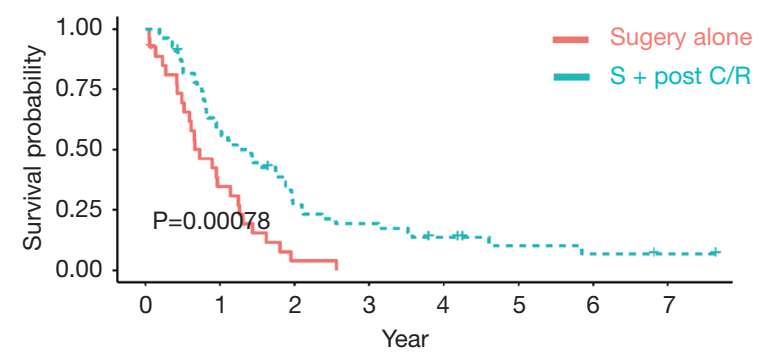

\begin{tabular}{cccccccl}
\multicolumn{2}{c}{ Event/at risk } & \multicolumn{4}{c}{ Survival probability (\%) } & & Median (95\% Cl) \\
$26 / 27$ & 100 & 33.3 & 3.7 & 0 & 0 & 0 & $8.7(6.24-15.2)$ \\
$48 / 55$ & 100 & 56.1 & 25.5 & 18.2 & 10.9 & 5.5 & $16.99(10.97-23.4)$
\end{tabular}
B

Stage III patients with tumor size $>8 \mathrm{~cm}$

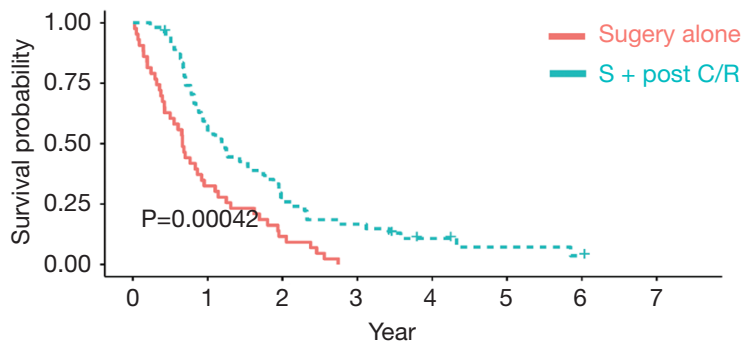

Event/at risk Survival probability (\%) Median $(95 \% \mathrm{Cl})$

$\begin{array}{llllllll}43 / 43 & 100 & 32.6 & 11.6 & 0 & 0 & 0 & 7.95(5.09-13.2)\end{array}$

50/55 $100 \quad 54.5 \quad 27.3 \quad 16.4 \quad 7.2 \quad 3.6 \quad 14.75(10.97-22.5)$

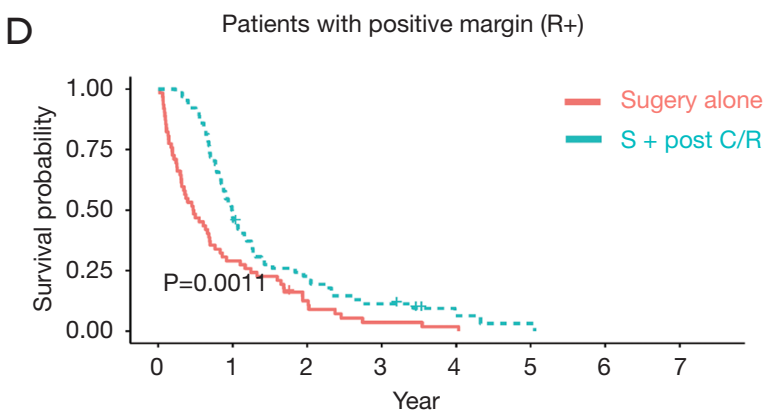

Event/at risk Survival probability (\%) Median $(95 \% \mathrm{Cl})$

$\begin{array}{llllllll}61 / 62 & 100 & 29.0 & 11.3 & 3.2 & 1.6 & 0 & 5.67(3.81-8.38)\end{array}$

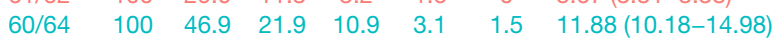

Figure 4 Survival curves according to treatment strategies. (A) OS of stage III patients; (B) OS of stage III patients whose tumor size is greater than $8 \mathrm{~cm}$; (C) OS of R0 patients with positive lymph nodes; (D) OS of R+ patients. OS, overall survival; $\mathrm{S}+$ post C/R, surgery with postoperative chemotherapy and/or radiotherapy; R0, negative margins; R+, positive margins.

There have been existing heated debates on GLP treatment strategies. This study evaluated the efficacy of different treatment strategies for patients with non-metastatic GLP. For all patients with non-metastatic GLP, our data showed $\mathrm{S}+\mathrm{C} / \mathrm{R}$ was associated with the best survival outcome in general. In a study on 54 patients with GLP from the UK, Thompson et al. (10) reported that a combination of surgery and chemotherapy resulted in a higher median survival (24.8 months) than surgery alone (9.9 months). Another study, which was based on information from the Surveillance, Epidemiology, and End Results (SEER) database, also found surgery with radiation therapy yielded a better median survival than surgery alone and radiation alone (11). Compared to our data, higher median survival for surgery alone (13 vs. 8.38 months) and a combination of surgery and radiation (31 vs. 13.90 months) was observed.
Since there were more stage III patients and fewer stage I patients in our cohort than in the previous study (number of patients: stage I, 16 vs. 72; stage II, 53 vs. 59; and stage III, $200 v s .135$ ), this phenomenon may be related to the cohorts containing different proportions of patients in each TNM stage.

According to our study, the proportions of patients with different TNM stages were quite similar between surgery alone and $\mathrm{S}+\mathrm{C} / \mathrm{R}$. This suggested that there was no prior established specific treatment modality for non-metastasis GLP patients with different stages. As the subgroup of patients who received preoperative chemotherapy/ radiotherapy used different staging systems (ypTNM) and the sample size of this subgroup was small, we just estimated the efficacy of surgery with postoperative chemotherapy/ radiotherapy in different stages. What is surprising was that 
surgery + post $\mathrm{C} / \mathrm{R}$ seemed not to have more advantages over surgery alone for patients with stage II disease. This indicated surgery alone may be sufficient to control recurrence for GLP patients in stage II. Further study with a larger sample size and a clearer surgical approach should be taken to explore the efficacy of surgery alone for GLP patients in stage II. However, $\mathrm{S}+$ post $\mathrm{C} / \mathrm{R}$ brought a better survival benefit to stage III patients. As mentioned before, the average tumor size of GLP is $8.9 \pm 6.1 \mathrm{~cm}(18)$. Several studies defined the gastric cancer with a diameter of $8 \mathrm{~cm}$ or more as large gastric cancer (19-21). Nevertheless, there has been few studies that explored the efficacy of different treatment strategies for non-metastatic patients when it comes to the different tumor size. In this study, we found the addition of chemotherapy and/or radiotherapy to surgery exhibited a nonsignificant survival benefit for stage III patients with a tumor size of less than or equal to $8 \mathrm{~cm}$. However, there was a strong evidence of a survival benefit for $\mathrm{S}+$ post $\mathrm{C} / \mathrm{R}$ in stage III patients with a tumor size of $>8 \mathrm{~cm}$. This is the first time that patient stages and tumor sizes have been linked to strategies for treating GLP.

Although surgery can improve the OS in general, patients with GLP who received surgery alone or S + C/R still have a poor prognosis. One of the important reasons was that $\mathrm{R}+$ resection, which was a poor prognostic factor according to our data, was more common in patients with GLP than non GLP patients (18). Kodera et al. reported a R0 resection rate of $46 \%$ with the median survival of 30.2 months, while palliative resection group was 8.2 months and nongastrectomy group was 7.8 months (22). In our study, there were up to $46.98 \%$ patients with positive margins with the median survival of 9.79 months. We further explored the efficacy of $\mathrm{S}+$ post $\mathrm{C} / \mathrm{R}$ for different surgical margins. Negative margins and negative regional lymph nodes were associated with lower locoregional recurrence. As expected, surgery alone seemed to be sufficient to control recurrence for R0 patients with negative lymph nodes. Intergroup 0116 (INT-0116), a randomized phase III trial, demonstrated that postoperative chemoradiotherapy as a rational standard for R0 gastric cancer with positive lymph nodes (23). The Artist trial also proved the therapeutic benefit of radiochemotherapy after curatively resected gastric cancer for patients with lymph node metastasis (24). Consistent with that, we found GLP patients with positive lymph nodes had a long term survival benefit of $\mathrm{R} 0$ resection with postoperative $\mathrm{C} / \mathrm{R}$. As for patients with positive margins, there was an obvious survival benefit for $\mathrm{R}+$ patients who received $\mathrm{S}+$ post $\mathrm{C} / \mathrm{R}$ compared to surgery alone. It was consistent with the 2019 NCCN guidelines, recommending $\mathrm{R}+$ gastric cancer patients to receive postoperative chemotherapy or chemoradiation if they did not receive perioperative $\mathrm{C} / \mathrm{R}(25)$.

Recently, scholars have focused on the necessity of radiotherapy in comprehensive treatment of gastric cancer (24). We therefore explored the efficacy of surgery + chemotherapy and surgery + chemoradiotherapy for GLP patients with positive margins. However, surgery + chemoradiotherapy did not yield a better survival benefit than surgery + chemotherapy. It indicated that local treatments like postoperative radiotherapy might not able to provide an added benefit for GLP disease with positive margins, due to its highly aggressive biological behavior and metastasis potential.

Taken together, we found surgery was essential for patients with non-metastatic GLP, while postoperative chemotherapy and/or radiation could improve the OS in patients who received $\mathrm{R} 0$ resection with positive lymph nodes and patients who received $\mathrm{R}+$ resection. However, the efficacy of existing treatments for non-metastasis is limited. We still need to explore more effective treatments. Some studies proved that extended multiorgan resection performed to reduce the recurrence rate failed to improve the OS than traditional surgery (26) and should be avoided if possible due to high postoperative morbidity and mortality (27). Other researchers have conjectured patients with stage III scirrhous gastric carcinoma, which is a type of gastric cancer equivalent to GLP in some studies, should undergo gastrectomy with extended lymphadenectomy due to a high rate of positive lymph nodes (28). However, this type of lymphadenectomy might increase surgery related morbidity and mortality (29). JCOG0501, a randomized phase III trial, demonstrated the safety of neoadjuvant chemotherapy followed by D2 gastrectomy for patients with Bormann type 4 or large (a tumor size of equal to or more than $8 \mathrm{~cm}$ ) type $3(19)$, while the efficacy of this strategy remains to be explored. Given these previous researches, attaining a satisfactory prognosis seems difficult for GLP patients. Further research should be undertaken to investigate the outcomes of specific surgical treatments, such as gastrectomy with extended lymphadenectomy, in combination with neoadjuvant and/or adjuvant chemoradiotherapy.

To the best of our knowledge, this is the first systematic research using a large national database to analyze the treatment strategies and prognostic factors of nonmetastatic GLP. However, this study has several limitations. 
First, since the NCDB does not provide any information on causes of death, disease-free survival could not be investigated. Second, there is no information in NCDB regarding the rational to choose treatment modality, which will lead to the patient selection bias. The observed results between $\mathrm{C} / \mathrm{R}$ alone and surgery might be influenced by the selection bias. Third, clinical information on the majority of patients who received $\mathrm{C} / \mathrm{R}$ was unclear. And there were only a few patients who received $\mathrm{C} / \mathrm{R}$ in stage II, stage III, R0 and $\mathrm{R}+$ groups. Therefore, we did not discuss the efficacy of $\mathrm{C} / \mathrm{R}$ alone in these groups.

\section{Conclusions}

In conclusion, evidence from NCDB indicated that surgery remained the fundamental role in improving the OS of patients with non-metastatic GLP. Furthermore, surgery with postoperative $\mathrm{C} / \mathrm{R}$ would benefit patients who were stage III with large-sized tumors $(>8 \mathrm{~cm})$, patients with negative resection margins and positive lymph nodes, and/ or patients with positive resection margins.

\section{Acknowledgments}

Funding: None.

\section{Footnote}

Reporting Checklist: The authors have completed the STROBE reporting checklist. Available at http://dx.doi. org/10.21037/atm-20-2785b

Conflicts of Interest: All authors have completed the ICMJE uniform disclosure form (available at http://dx.doi. org/10.21037/atm-20-2785b). The authors have no conflicts of interest to declare.

Ethical Statement: The authors are accountable for all aspects of the work in ensuring that questions related to the accuracy or integrity of any part of the work are appropriately investigated and resolved. The study was conducted in accordance with the Declaration of Helsinki (as revised in 2013).

Open Access Statement: This is an Open Access article distributed in accordance with the Creative Commons Attribution-NonCommercial-NoDerivs 4.0 International License (CC BY-NC-ND 4.0), which permits the non- commercial replication and distribution of the article with the strict proviso that no changes or edits are made and the original work is properly cited (including links to both the formal publication through the relevant DOI and the license). See: https://creativecommons.org/licenses/by-nc-nd/4.0/.

\section{References}

1. Vivier-Chicoteau J, Lambert J, Coriat R, et al. Development and internal validation of a diagnostic score for gastric linitis plastica. Gastric Cancer 2020;23:639-47.

2. Agnes A, Estrella J, Badgwell B. The significance of a nineteenth century definition in the era of genomics: linitis plastica. World J Surg Oncol 2017;15:123.

3. The Diseases of the Stomach, with an Introduction on Its Anatomy and Physiology; Being Lectures Delivered at St. Thomas's Hospital. Br Foreign Med Chir Rev 1859;24:109-19.

4. Shan GD, Xu GQ, Li YM. Endoscopic ultrasonographic features of gastric linitis plastica in fifty-five Chinese patients. J Zhejiang Univ Sci B 2013;14:844-8.

5. Luu C, Thapa R, Woo K, et al. Does histology really influence gastric cancer prognosis? J Gastrointest Oncol 2017;8:1026-36.

6. Kodera Y, Ito S, Mochizuki Y, et al. The number of metastatic lymph nodes is a significant risk factor for bone metastasis and poor outcome after surgery for linitis plastica-type gastric carcinoma. World J Surg 2008;32:2015-20.

7. Endo K, Sakurai M, Kusumoto E, et al. Biological significance of localized Type IV scirrhous gastric cancer. Oncol Lett 2012;3:94-9.

8. Schauer M, Peiper M, Theisen J, et al. Prognostic factors in patients with diffuse type gastric cancer (linitis plastica) after operative treatment. Eur J Med Res 2011;16:29-33.

9. Pedrazzani C, Marrelli D, Pacelli F, et al. Gastric linitis plastica: which role for surgical resection? Gastric Cancer 2012;15:56-60.

10. Thompson RJ, Ranaghan L, Kennedy R, et al. Survival following operative management of gastric linitis plastica compared with non-operative management. Ann R Coll Surg Engl 2017;99:228-32.

11. Chang JM, Lara K, Gray R, et al. Clinical Outcomes after Surgery for Linitis Plastica of the Stomach: Analysis of a Population Cancer Registry. Am Surg 2017;83:23-9.

12. Jafferbhoy S, Shiwani H, Rustum Q. Managing Gastric Linitis Plastica: Keep the scalpel sheathed. Sultan Qaboos University Medical Journal 2013;13:451-3. 
13. Hamy A, Letessier E, Bizouarn P, et al. Study of survival and prognostic factors in patients undergoing resection for gastric linitis plastica: a review of 86 cases. Int Surg 1999;84:337-43.

14. Ikoma N, Agnes A, Chen HC, et al. Linitis Plastica: a Distinct Type of Gastric Cancer. J Gastrointest Surg 2020;24:1018-25.

15. Bilimoria KY, Stewart A, Winchester D, et al. The National Cancer Data Base: a powerful initiative to improve cancer care in the United States. Ann Surg Oncol 2008;15:683-90.

16. Boffa DJ, Rosen J, Mallin K, et al. Using the National Cancer Database for Outcomes Research: A Review. JAMA Oncol 2017;3:1722-8.

17. Amin M, Edge S, Greene F, et al. AJCC cancer staging manual. 8th Edition. New York: Springer, 2017.

18. Blackham AU, Swords D, Levine E, et al. Is Linitis Plastica a Contraindication for Surgical Resection: A MultiInstitution Study of the U.S. Gastric Cancer Collaborative. Ann Surg Oncol 2016;23:1203-11.

19. Terashima M, Iwasaki Y, Mizusawa J, et al. Randomized phase III trial of gastrectomy with or without neoadjuvant S-1 plus cisplatin for type 4 or large type 3 gastric cancer, the short-term safety and surgical results: Japan Clinical Oncology Group Study (JCOG0501). Gastric Cancer 2019;22:1044-52.

20. Irino T, Sano T, Hiki N, et al. Diagnostic staging laparoscopy in gastric cancer: a prospective cohort at a cancer institute in Japan. Surg Endosc 2018;32:268-75.

21. Kobayashi O, Tsuburaya A, Yoshikawa T, et al. The efficacy of gastrectomy for large gastric cancer. Int J Clin Oncol 2006;11:44-50.

Cite this article as: Song X, Shi Y, Shi T, Liu B, Wei J, Wang J. The efficacy of treating patients with non-metastatic gastric linitis plastica using surgery with chemotherapy and/or radiotherapy. Ann Transl Med 2020;8(21):1433. doi: 10.21037/atm20-2785b
22. Kodera Y, Nakanishi H, Ito S, et al. Detection of disseminated cancer cells in linitis plastica-type gastric carcinoma. Jpn J Clin Oncol 2004;34:525-31.

23. Smalley SR, Benedetti J, Haller D, et al. Updated analysis of SWOG-directed intergroup study 0116: a phase III trial of adjuvant radiochemotherapy versus observation after curative gastric cancer resection. J Clin Oncol 2012;30:2327-33.

24. Lee J, Lim D, Kim S, et al. Phase III trial comparing capecitabine plus cisplatin versus capecitabine plus cisplatin with concurrent capecitabine radiotherapy in completely resected gastric cancer with D2 lymph node dissection: the ARTIST trial. J Clin Oncol 2012;30:268-73.

25. National Comprehensive Cancer Network. Gastric cancer (Version 1.2019). Available online: https://www.nccn. org/professionals/physician_gls/pdf/gastric.pdf, accessed March 14, 2019.

26. Furukawa H, Hiratsuka M, Iwanaga T, et al. Extended surgery--left upper abdominal exenteration plus Appleby's method--for type 4 gastric carcinoma. Ann Surg Oncol 1997;4:209-14.

27. Xiao H, Ma M, Xiao Y, et al. Incomplete resection and linitis plastica are factors for poor survival after extended multiorgan resection in gastric cancer patients. Sci Rep 2017;7:15800.

28. Otsuji E, Kuriu Y, Okamoto K, et al. Outcome of surgical treatment for patients with scirrhous carcinoma of the stomach. Am J Surg 2004;188:327-32.

29. Ramos MF, Pereira M, Dias A, et al. Surgical outcomes of gastrectomy with D1 lymph node dissection performed for patients with unfavorable clinical conditions. Eur J Surg Oncol 2019;45:460-5. 